\title{
Editorial
}

\section{Risk Classification and Public Policy}

\section{Reimund Schwarze}

Deutsches Institut für Wirtschaftsforschung (DIW), Berlin and Europa-Universität Viadrina Frankfurt (Oder), Germany.

E-mail: rschwarze@diw.de

The Geneva Papers (2006) 31, 187-189. doi:10.1057/palgrave.gpp.2510084

The economic effects of prohibiting the use of sex and other potentially discriminatory risk classifiers such as age, race or nationality are subject of a lasting debate among insurance economists. It can be traced back to the $1950 \mathrm{~s}^{1}$ and received broad economic attention in the 1980s when spiralling car insurance premiums in the U.S. were blamed on tariff regulations prohibiting the use of sex, age and location as risk classifiers. ${ }^{2}$ The majority view today is that the problem of adverse selection arises if insurance firms are unable to distinguish between different types of risks. ${ }^{3}$ Risk classification, in this view, is not only a necessary but also a good thing. The leading justifications for risk classification are that without risk classification, low risks are unfairly forced to subsidize high risks, and that risk classification promotes socially beneficial efforts to prevent loss.

Dissenting authors have demonstrated that the efficiency cost of prohibiting risk classification are much less than commonly stated. ${ }^{4}$ It depends critically on the propensity of people to self-insure (price elasticity of demand). It will therefore differ among branches of insurance, for example be higher for voluntary retirement schemes where savings alternatives exist than for life insurance with few substitutes. It will also differ according to regulatory embeddings, e.g., be non-existent in mandatory insurance schemes (if properly enforced). Critics have also demonstrated that risk classification can be socially wasteful. ${ }^{5}$ This is the case if it becomes purely selective. In a world of competitive voluntary insurance, eliminating the most risky from an insurance pool is a powerful tool of competition. It reduces the average cost of insuring the members of the pool, allowing the insurer to offer a lower price and, possibly, obtain a greater profit. This adverse selection "on the side of the insurers", 6 while individually rational, produces a result that is contrary to the interest of society. It inhibits the ability of insurance to spread risk.

The latest blow against risk classification comes from the EU's directive implementing the principle of equal treatment between women and men in the supply of goods and services. This so-called "Gender Equality Directive" aims to prohibit the

\footnotetext{
${ }^{1}$ Muir (1957).

${ }^{2}$ Harrington and Doerpinghaus (1993).

${ }^{3}$ Crocker and Snow (2000).

${ }^{4}$ Thomas (2004).

${ }^{5}$ Rea (1992).

${ }^{6}$ Baker (2003).
} 
discrimination based on sex, particularly in the field of insurance. ${ }^{7}$ After the EU Commission's earlier proposal met stiff resistance from the insurance industry, ${ }^{8}$ the European Council allowed insurers to deviate from the principle of equal treatment of men and women as long as they can prove that gender is a decisive factor in assessing risk. The EU Commission was ordered to monitor the implementation of this exemption and to review the situation after a 5-year period (in 2008). From now on insurers will have to keep on proving statistically that they are not using gender for discriminatory purposes.

This often heated debate has motivated the Geneva Association to devote its 11th joint seminar with the European Association of Law and Economics to explore the issue of "Risk Classification and Public Policy". The seminar, which was held on 16th and 17th of June 2005 at the German Institute for Economic Research (DIW) in Berlin and supported by the German Insurance Association, focused on the economic effects of banning information on age, sex or genetics for the purpose of risk classification in insurance contracts. ${ }^{9}$ It also touched upon legal issues of the current nondiscrimination legislation in the EU and in Canada.

This special issue of the Geneva Papers publishes four papers of this seminar which were selected by external reviewers; some other contributions are still in the process of review. It is opened by Yves Thiery and Caroline Van Schoubroeck of the University of Leuven looking into the legal and political aspects of the current non-discrimination legislation of the EU. They introduce the concept of "risk solidarity" in an attempt to bridge the thinking of legal scholars and scholars from insurance economics. Norma Nielson of the University of Calgary (in a joint paper with Mary Kelly) look into the practical and empirical aspects of this debate in the context of automobile insurance. Specifically, they provide evidence that age is an important factor to determine the frequency and severity of auto accidents and discuss the effects of using alternative variables such as number of years licensed, driving record, and insurance scores. Though obviously none of these other variables is able to capture the real difference in the population of insureds their use can minimize the cost of banning age as a classifier to a considerable extent. In the context of German private health insurance, Oliver Riedel of the University of Giessen finds that the prohibition of gender-based primary premium differentiation could be compensated to about $2 / 3$ by secondary premium differentiation; the extent of risk-shifting (back) to the insureds would however be substantial. Michael Hoy from the University of Guelph (Ontario/Canada) completes this section by a paper that summarizes and extends the economic background of this debate. He looks into the questions: Why do insurers need immutable individual characteristics as risk classifiers, how will the ban to use this information affect the insurance market, and how will it affect social welfare? As an important result he finds that restrictions on risk classification will unambiguously reduce social welfare if the fraction of high-risk types in the population exceeds a critical level. However, if the

\footnotetext{
${ }^{7}$ Council of the European Union (2004).

${ }^{8}$ CEA (2006).

${ }^{9} 11$ th Joint Seminar of the European Association of Law and Economics (EALE) and The Geneva Association, Berlin, 16-17 June 2005, Working Paper Series - Etudes et Dossiers No. 299/July 2005 (see also: http:/www.diw.de/english/produkte/veranstaltungen/eale_ga2005/report.html, acc.: 3.2.2006).
} 
fraction of high-risk types is sufficiently small, then it is possible that banning risk classification can even enhance social welfare under a veil of ignorance-inspired social welfare approach. A balanced empirical approach is therefore needed to establish whether risk classification is socially beneficial or detrimental. However, a presumption can be made that negative social welfare effects will be more likely for a ban on gender and age (with large groups of insureds affected) compared to genetic tests (with small groups of insureds affected).

This set of papers provides some important messages for policymakers and political activists in this field. The editors of this journal invite other authors to join this debate because we believe that this issue will become ever more important as nondiscrimination becomes the cornerstone of European social policy. ${ }^{10}$

\section{References}

Baker, T. (2003) 'Containing the promise of insurance: adverse selection and risk classification', in R. Ericson (ed) Risk and Morality, Toronto: University of Toronto Press.

Comité Européen des Assurances (CEA) (2006) 'Equality of treatment between men and women. Prohibition of private insurance calculation on a gender-dependent basis', Letter sent on 28 May 2003 to Commissioner Anna Diamantopoulou (available at: www.cea.assur.org/cea/v1.1/posi/pdf/uk/ position174.pdf, accessed: 3.2 .2006$)$.

Council of the European Union (2004) Council Directive 2004/113/EC of 13 December 2004 implementing the principle of equal treatment between men and women in the access to and supply of goods and services, Official Journal L 373, 21/12/2004, pp. 0037-0043.

Crocker, K.J. and Snow, A. (2000) 'The theory of risk classification', in G. Dionne (ed) Handbook of Insurance, Dordrecht: Kluwer Academic Publisher, pp. 245-276.

EU Commission (2000) Communication from the Commission to the Council, the European Parliament and the Social Committee: Social Policy Agenda, COM(2000)0379 final, Brussels.

Harrington, H.I. and Doerpinghaus, S.E. (1993) 'The economics and politics of automobile insurance rate classification', Journal of Risk and Insurance 60: 59-84.

Mabbett, D. (2000) 'Social regulation and the social dimension in Europe: The example of insurance', European Journal of Social Security 2(4): 241-257.

Muir, J.M. (1957) Principles and Practices in Connection with Classification Ratings Systems For Liability Insurance as applied to Private Passenger Automobiles, Proceedings of the Casuality Actuarial Society, 1957.

Rea, S.A. (1992) 'Insurance classifications and social welfare', in G. Dionne (ed) Contributions to Insurance Economics, Boston: Kluwer Academic Publishers, pp. 377-396.

Thomas, G. (2004) Some novel perspectives on risk classification, unpublished paper (available at http:// www.guythomas.org.uk/pdf/NovPer-Dec05.pdf, accessed: 3.2.2006).

${ }^{10}$ EU Commission (2000), Mabbett (2000). 